\title{
Silicone Doped Chitosan-Acrylamide Coencapsulated Urea Fertilizer: An Approach to Controlled Release Fertilizers
}

\author{
Sempeho Ibahati Siafu \\ Department of Distance Education, Institute of Adult Education, P.O. Box 20679, Dar es Salaam, Tanzania \\ Correspondence should be addressed to Sempeho Ibahati Siafu; sempeho@iae.ac.tz
}

Received 2 September 2016; Revised 19 January 2017; Accepted 23 January 2017; Published 12 February 2017

Academic Editor: María J. Lázaro

Copyright (c) 2017 Sempeho Ibahati Siafu. This is an open access article distributed under the Creative Commons Attribution License, which permits unrestricted use, distribution, and reproduction in any medium, provided the original work is properly cited.

In the absence of special management practices, urea is known to undergo chemical transformations resulting in severe losses $(\approx 60-70 \%)$ of total fertilizer applied. In an attempt to design urea controlled release fertilizers in order to counterbalance the 60$70 \%$ loss, urea was cross-linked with chitosan and acrylamide under refluxed in situ copolymerization technique; the procedures were repeated with silicone doping prior cross-linking with MBA. The particles were characterized with FTIR/ATR, EDX, XRD, and SEM. The IR bands observed within $3426-409 \mathrm{~cm}^{-1}$ revealed the formation of new bands after coencapsulation for the $v_{\gamma} \mathrm{N}-\mathrm{H}$, $\nu_{\beta} \mathrm{N}-\mathrm{H}, \nu \mathrm{OH}, \nu_{s} \mathrm{NH}_{2}, \nu \mathrm{CH}_{2}, \nu \mathrm{C}=\mathrm{O}, \delta^{\prime} \mathrm{NH}_{2}, \nu \mathrm{C}=\mathrm{C}, \delta \mathrm{NH}_{2}, \nu \mathrm{C}-\mathrm{N}, \beta \mathrm{CH}_{3}, \$ \mathrm{C}-\mathrm{N}, \gamma \mathrm{NH}_{2}, \nu \mathrm{C}=\mathrm{O}$, and $\$ \mathrm{CH}_{2}$. Crystallinity indices for urea with and without silicone doping were found to be $50.9 \%$ and $72.1 \%$, respectively, with a distinctive split peak at $(d) 12.30^{\circ}$. The formation of Microdunes and Microballs 3D network sized $0.64 \mu \mathrm{m}$ was noted. Release profiles demonstrated that $80 \% \mathrm{~N}$ was released in a period of 30 days at RT and $\mathrm{pH}$ 7. The release patterns exhibited linear and deformed sigmoid release models. Empirically, the findings demonstrated that it is possible to design urea controlled release fertilizers with varying particle sizes and morphologies by using chitosan-acrylamide coencapsulation.

\section{Introduction}

Owing to its being a low cost nitrogen fertilizer with a high nitrogen content of about $46 \%$, urea fertilizer has been used (within Tanzania in particular) to supplement crop plants of nitrogen [1-3]. Urea has been useful in horticultural practices, enrichment of lawns or sods, meadows, prairies, and road-side protective grasses necessary to control erosion by the road sides, orchards, in cereals plantation, and so forth, such that its advanced research is vital for the economic growth of any country like Tanzania whose economy depends on agriculture [4-8].

On the contrary, despite being such an economically and agronomically useful chemical material urea is limited for the reason that: its availability to crop plants is less than $50 \%$ with up to $60-70 \%$ loss of the sum applied in the soil due to vaporization, hydrolysis, and quick leaching rendering its fertilizer use efficiency (FUE) low [3, 9]. As a consequence, attempts involving the use of excipients molecules to obtain controlled release urea formulations have been done to maximize the efficiency and availability to crop plants to about $70 \%$ or more. These include the synthesis of urea-aldehyde condensation products, such as ureaformaldehyde (UF), urea triazone (UT), crotonylidene diurea (CDU), and chemically decomposing compounds, such as isobutylidenediurea (IBDU) [10] and urea granules coated by hydrophobic polymers or as matrices such as polyolefins and rubber and gel-forming polymers (hydrogels) which are hydrophilic in nature and sulphur-coated urea (SCU).

Essentially, several polymers and polymer resins are known to be used in the designing of urea controlled release fertilizer (CRF) formulations including acrylamide, urethane resin, epoxy resin, alkyd resin, unsaturated polyester resin, phenol resin, urea resin, melamine resin, phenol resin, and silicon resin along with a good number of natural biopolymeric materials such as chitosan which has been used in this study [10]. To the best our knowledge, no attempts have ever been done to design urea CRF formulations by using copolymerization of chitosan and acrylamide along with silicone doping. In that case, we have described in 
this paper the preparation of urea CRF formulation as an approach to controlled release systems (CRSs) using simple and inexpensive starting materials including silicone oil, chitosan biopolymer, acrylamide, and urea synthetic fertilizer.

Chitosan was used in this study owing to its inherent properties such as high swelling ratio [11], water-retention capacity [12], antimicrobial activity, availability, low toxicity, biodegradability, capability for high cross-linking, and low processing cost [13-15]. Also, the nanoparticles resulting from chitosan are known to exhibit spherical shapes and uniform sizes [16]; similarly, the complexes formed between chitosan with other bioactive species (urea in our context) along with other polymers are known in modifying the release characteristics of the named CRSs formulated [17]. On the other hand, we have stated elsewhere [10] that "polyacrylamide is known to reduce soil erosion" and also it is biodegradable $[18,19]$; thus polyacrylamide was chosen to be used along with chitosan in the urea copolymerization process.

In due course, the synthesized urea CRF formulation is expected to augment crops grain yield and straw yield as well as enrich soil with nitrogen thereby increasing its nutritional status and also the efficacy of Conventional Chemical Fertilizers (CCFs) such as urea [20]. In fact, the efficacy of CRFs is known to be more than four times higher than CCFs which indicates that even $1 / 4$ th of chemical fertilizers can be made more effective with organic blending into CRSs [20].

\section{Materials and Methods}

2.1. Materials. Urea (ACS reagent, 99.0-100.5\%) was supplied by Sigma Aldrich, deionized distilled (DI) water was supplied by Professor Kim's lab, chitosan powder was supplied by Sigma Aldrich, acetic acid glacial (99.7\%) was supplied by Duksan Pure Chemicals, Ansan city, Kyungki-do, Korea, $2,2^{\prime}$-azobisisobutyronitrile (AIBN) $(\geq 98.0 \%)$ was supplied by Samchun Pure Chemicals Co. Ltd., Gyonggi-do, Korea, $\mathrm{CCl}_{4}(\geq 99.0 \%)$ was supplied by Junsei Chemical Co., Ltd., Japan, N,N'-methylenebisacrylamide (MBA) ( $\geq 98.0 \%)$ was supplied by Samchun Pure Chemicals Co. Ltd., Gyonggido, Korea, acrylamide ( $\geq 98.5 \%$ ) was supplied by Samchun Pure Chemicals Co. Ltd., Gyonggi-do, Korea, $n$-hexane was supplied by was supplied by Sigma Aldrich, and silicone oil was supplied by Sigma Aldrich.

\subsection{Methods}

2.2.1. Preparation of Chitosan Solution. A chitosan solution (2\%) was prepared by dissolving $10 \mathrm{~g}$ chitosan powder into $500 \mathrm{~mL}$ of $10 \%$ glacial acetic acid to get the $\mathrm{pH}$ of the solution in a range of 4-5. The solution was stirred for 40 hours at RT until a gold colour was obtained.

2.2.2. Preparation of Chitosan-Acrylamide Encapsulated Urea. AIBN $(0.2 \mathrm{~g})$ was agitated with $30 \mathrm{~mL}$ of $\mathrm{CCl}_{4}$ in the 3necked round bottomed flask ( $\mathrm{RBF}$ ) containing $0.4 \mathrm{~g}$ of $\mathrm{MBA}$ and the apparatus was set under hood and was run for 20 minutes under $\mathrm{N}_{2}$ atmosphere at $60^{\circ} \mathrm{C}$. Thereafter, a chitosan solution prepared which contained $7 \mathrm{~g}$ of acrylamide and $8 \mathrm{~g}$ of urea was introduced and stirred under reflux overnight.
The product was washed with $n$-hexane and dried at $60^{\circ} \mathrm{C}$ with a vacuum oven; it was then labelled as CPAM-1.

2.2.3. Preparation of Chitosan-Acrylamide Encapsulated Urea with Silicone Oil Doping. The procedures for the preparation of chitosan-acrylamide encapsulated urea (described above) were repeated with the following modifications. Stirring under reflux was done for six hours after which $1 \mathrm{~mL}$ of silicone oil was spiked with a syringe as dopant and then continued stirring overnight. The product was washed with $n$-hexane and dried under vacuum oven and it was then labelled as CPAM.

2.2.4. Release Experiments. Release experiments were carried out in water ( $\mathrm{pH} \mathrm{7)}$ as media as follows. 5 grams of the prepared CRFs was dissolved in $100 \mathrm{~cm}^{3}$ of distilled water at room temperature (RT). The content of released urea from the encapsulated fertilizer was collected by using column extraction method in which a PVC-based column measuring $30 \mathrm{~cm}$ long and $5 \mathrm{~cm}$ in diameter was fitted with gauze at the bottom end and then capped. The procedures were adopted with modification from [21]. Each column was leached at an interval of 24 hours for a period of 30 days owing to the fact that a pilot experiment had revealed that about $80 \%$ of fertilizer could be released in that time range. The amount of nitrogen contained in the leachate was determined by using Kjeldahl method (total Kjeldahl N) which involves three steps, namely, digestion, distillation, and titration. Each experiment was done in triplicate for each sample and the average values were used for plotting the release profiles.

\subsubsection{Characterization}

Infrared Spectroscopy. FTIR-ATR analysis was performed at wavelengths between 7500 and $360 \mathrm{~cm}^{-1}$ using a Bruker Optic GmbH (alpha model, Laser class 1) Spectrometer with attenuated total reflectance.

$X$-Ray Diffraction. The XRD analysis was carried out using Rigaku Corp. D/Max-2500/PC X-ray Diffractometer was equipped with a back monochromator operating at $40 \mathrm{kV}$ and $100 \mathrm{~mA}$ at the scanning range of $5^{\circ}-80^{\circ}$ with a step size of $0.1^{\circ}$ and a time/step of $1 \mathrm{~s}$ using copper cathode $(\mathrm{Cu} \mathrm{K} \alpha 1)$ as the X-ray source $(\lambda=1.54056 \AA)$.

Scanning Electron Microscopy (SEM). The samples surfaces morphology was investigated by using Field Emission Scanning Electron Microscopy (Hitachi S-4800, Japan). The accelerated voltage was $15 \mathrm{kV}$.

Particle Size Analysis. Image Tool software was used to analyze the size of particles from the SEM images. The plot for the average particles sizes was performed thereafter using Origin Pro 8 software. Kjeldahl apparatus was used for determining the amount of nitrogen released from CRFs.

\section{Results and Discussion}

3.1. Vibrational Spectra. The infrared spectra of urea as well as of the samples CPAM and CPAM-1 are shown in Figure 1 
TABLE 1: Band assignment for CPAM, urea, and CPAM-1.

\begin{tabular}{|c|c|c|c|c|}
\hline Urea & CPAM & CPAM-1 & Assignment & Reference \\
\hline 3426 & & & $v_{\gamma} \mathrm{N}-\mathrm{H}$ & {$[32,33]$} \\
\hline 3326 & 3339 & 3337 & $v_{\beta} \mathrm{N}-\mathrm{H}$ & {$[32,34]$} \\
\hline \multirow[t]{3}{*}{3253} & & & $\nu \mathrm{OH}$ (for $\mathrm{H}$ bonding associated with urea) & {$[35,36]$} \\
\hline & 3192 & 3187 & $v_{s} \mathrm{NH}_{2}$ & {$[26,27,31]$} \\
\hline & 2962 & 2935 & $\nu \mathrm{CH}_{2}$ & {$[28-31,37,38]$} \\
\hline \multirow[t]{3}{*}{1676} & & & $\nu \mathrm{C}=\mathrm{O} \& \delta^{\prime} \mathrm{NH}_{2}$ & {$[26,27,31,39,40]$} \\
\hline & 1648 & 1650 & $\nu \mathrm{C}=\mathrm{C}$ & {$[27,28]$} \\
\hline & 1601 & 1602 & $\delta \mathrm{NH}_{2}$ & \\
\hline 1588 & & & $\nu \mathrm{C}-\mathrm{N}$ & {$[29,39,40]$} \\
\hline \multirow[t]{4}{*}{1458} & 1448 & 1447 & $\beta \mathrm{CH}_{3} \& \$ \mathrm{C}-\mathrm{N}$ & {$[39,40]$} \\
\hline & 1412 & 1414 & $v$ of newly formed bonds & \\
\hline & & 1319 & $\nu$ of newly formed bonds ( $\mathrm{N}$-acetylglucosamine-acrylate) & \\
\hline & 1258 & & $\gamma \mathrm{NH}_{2}$ & \\
\hline \multirow[t]{5}{*}{1149} & & 1174 & $\nu \mathrm{C}=\mathrm{O} \& \$ \mathrm{CH}_{2}$ & {$[27,31]$} \\
\hline & 1081 & 1097 & & {$[41]$} \\
\hline & 1013 & & & {$[42-45]$} \\
\hline & 863 & & & \\
\hline & 791 & & & {$[42-46]$} \\
\hline
\end{tabular}

$\$$ : scissoring, $\Gamma$ : twisting, $\tau$ : torsion, and $\omega$ : wagging.

$\nu_{s}$ : symmetric stretching, $v_{\alpha}$ : asymmetric stretching, and $\delta$ : bending vibration.

whereas that of chitosan is given away in Figure 2. A summary of band assignments for urea, CPAM, and CPAM-1 samples is given in Table 1. Detailed band assignments for chitosan can be found elsewhere [22]. Typically, silicones have strong characteristics absorption bands in the mid infrared spectra range at 3000-2900, 1500-1490, 1260-1250, 1100, 1080$1000,770,751-750$, and $600 \mathrm{~cm}^{-1}$ [23-25]. The characteristics absorption peaks for the acrylamide are known to exist around 3365, 3352, 3180, 3030, 3011, 1675, 1654-1650, 1612, $1451,1430,1353,1325,1282,1138,1053,991,963,831,816$, $708,660,634-626,490$, and $225 \mathrm{~cm}^{-1}$ [26-28], whereas those of chitosan biopolymer (Figure 2) occur around 3750, $3367,3350,2927-2900,2875,1680,1662,1605,1559,1480$, $1426,1393,1375,1333,1320,1164-1150,1092-1080,1042,1025$, and $896-890 \mathrm{~cm}^{-1}[22,26,29-31]$. For pure urea fertilizer, the absorption bands are clearly seen in Table 1 which is approximately around the values we reported in $[9,10]$.

As indicated in Table 1, there were variations in the characteristic absorption bands observed relative to their original starting materials; this has revealed the fact that new bonds might have been formed as a result of copolymerization between chitosan-acrylamide with urea fertilizer and later with silicone oil used as dopant. The silicone doping was observed to be successful due to disappearance of typical silicone bands; however, the backbone of silicone structure was noticed due to the presence of its characteristics peaks around 1258, 1081, and $1013 \mathrm{~cm}^{-1}$. As seen in Figure 1, these characteristics bands were only seen in the CPAM; and they were absent in the CPAM-1 as a result of silicone doping.

The FTIR/ATR analysis also indicated encapsulation of urea fertilizer with copolymerization of chitosan and acrylamide materialized. Upon deducing peaks observed in

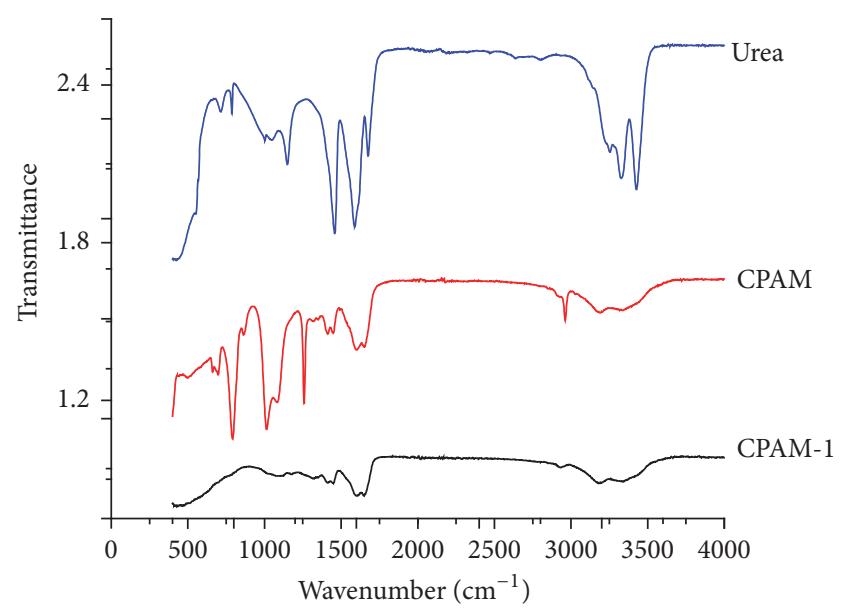

FIGURE 1: FTIR/ATR absorption band for urea CPAM-1 and CPAM.

Figure 1, it can easily be said that, among all characteristics of urea absorption bands, only bands at 3326 and $1458 \mathrm{~cm}^{-1}$ were unaltered after encapsulation. Besides, there were observable variations to these bands that the absorption band at $3326 \mathrm{~cm}^{-1}$ got transformed to $3339 \mathrm{~cm}^{-1}$ (for CPAM) and $3337 \mathrm{~cm}^{-1}$ (for CPAM-1) after encapsulation. This pointed out that the N-H in-phase bond stretching as well as the inphase $\mathrm{CH}_{3}$ bending vibrations were present but the outer $\mathrm{N}-\mathrm{H}$ bonds were completely covered with encapsulant such that the N-H out-phase bond stretching was absent after encapsulation. It was thus alleged that silicone caused a slight band shift from 3337 to $3339 \mathrm{~cm}^{-1}$ and from 1447 to $1448 \mathrm{~cm}^{-1}$ for CPAM-1 and CPAM, respectively. 


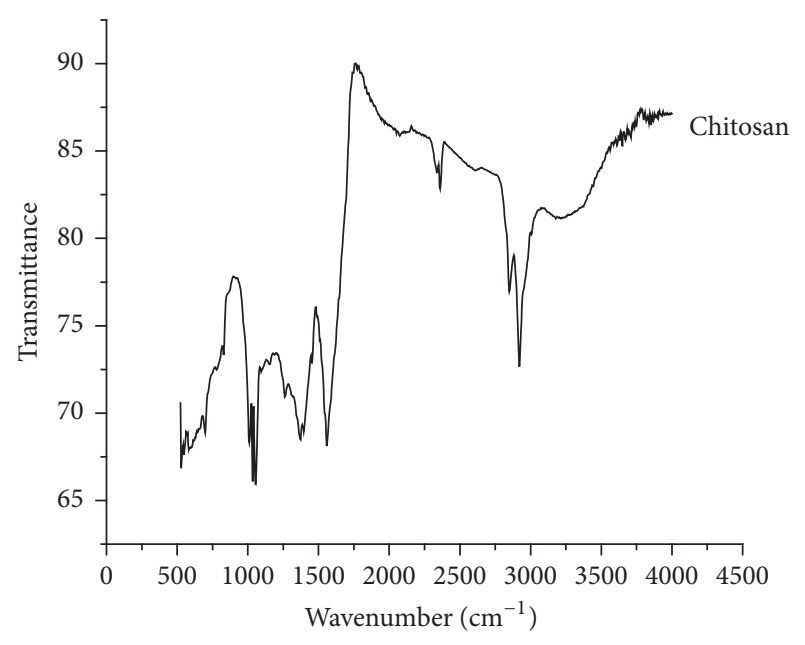

FIGURE 2: FTIR/ATR absorption band for chitosan biopolymer.

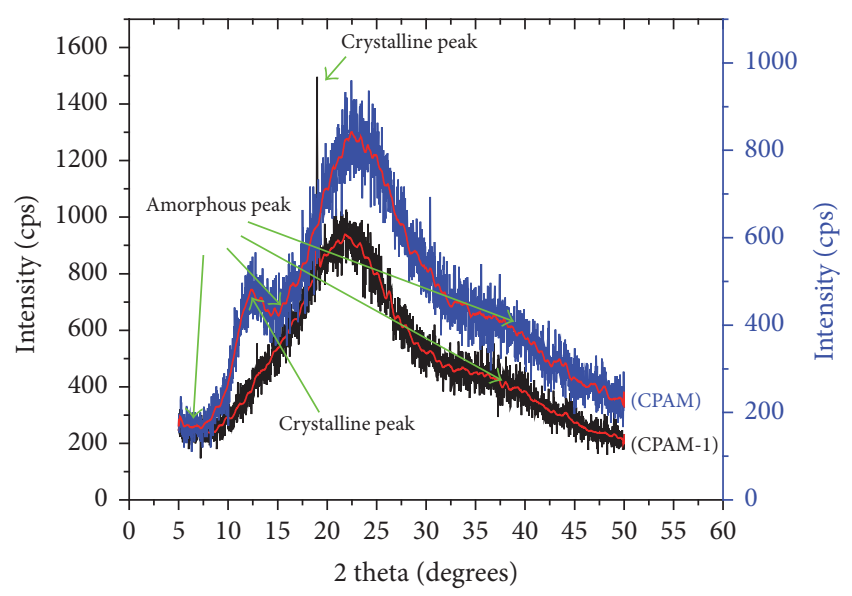

Figure 3: The X-ray diffraction pattern for CPAM-1 and CPAM.

3.2. X-Ray Analysis. The XRD patterns for the CPAM and CPAM- 1 were studied in the $2 \theta$ range of $5^{\circ}$ to $50^{\circ}$. The findings as shown in Figure 3 indicated that all the samples were more or less amorphous whereas the level of crystallinity was low. Based on the methods described by [47] crystallinity index (CI) was calculated from the ratio of the height of the 002 peak $\left(I_{002}\right)$ and the height of the minimum. That said, the CI was calculated for both CPAM and CPAM-1; the results indicated that CPAM-1 was more crystalline than CPAM; their respective crystallinity indices were $72.1 \%$ and $50.9 \%$. The peaks observed for CPAM were at $12.30^{\circ}(d)$ and $22.5^{\circ}$ $(s)$; both were broad and distinct. For CPAM-1, one high intensity peak was observed at $19.0^{\circ}(d)$ and another broad peak at $22.5^{\circ}$. The pattern of these broad peaks illustrated that the peak for CPAM-1 had a wider shoulder as compared to CPAM.

Essentially, the extra split peak $(d)$ at $12.30^{\circ}$ was considered to be distinctive for the CPAM and it can be used to identify CPAM from CPAM-1. The appearance of the split peak $(d)$ at $12.30^{\circ}$ for the CPAM was ascribed to the presence of $\mathrm{OH}^{-}$and $\mathrm{NH}_{2}$ groups from the chitosan which form stronger intermolecular hydrogen bonds upon copolymerization. The presence of silicone dopant which covered these functional groups caused a disappearance of this peak such that it was completely absent in the CPAM1. This suggested the fact that the backbone structure of chitosan was not deformed during copolymerization process but with silicone doping the backbone structure which disappeared indicating the existence of a strong interaction between chitosan-acrylamide-urea and silicone. Reflecting on the findings by [48], the waveband pattern observed for the CPAM curve revealed that chitosan structure acted as a copolymer framework during the coencapsulation process such that its original known structure [48] got modified into the waveband pattern observed in Figure 3. Similarly, in the CPAM the amorphous phase seemed to dominate the crystalline phase; this may suggest the impact of silicone on the crystallinity of the prepared composite CPAM-1.

3.3. SEM and Particle size Analysis. For the purpose of determining the particle size and sample morphology SEM images were taken and analyzed (Figures 4-6). The findings indicated that when urea fertilizer was cross-linked through copolymerization of acrylamide and chitosan biopolymer under the specified experimental conditions, the resulting composite materials exhibited what we have termed as the "Microballs" appearance. As can be seen in Figure 4, the Microballs were observed to be highly cross-linked and that each particle was strongly bonded to the other in a 3D network to form a beautiful sheet of numerous Microballs. Besides, when silicone was doped into the matrices of Microballs 3D network, a complete structural transformation was observed (Figure 5); a new phase (which was named "Microdunes") was observed to emerge following silicone doping. Indeed, a very beautiful wrinkled sheet of Microdunes developed at the expense of the Microballs thereby indicating the impact of silicone doping on the framework of CPAM-1 composite materials.

Comparatively, the surfaces of the Microballs were seen to be smooth while those of the Microdunes were seen to be rough or rather wrinkled. By instinct, this observation revealed that the surface area of the Microdunes could be higher than that of the Microballs. Besides, the Microballs were observed to be highly cross-linked and interconnected than the Microdunes. That is to say, for the purpose of designing CRF formulations with roundish particles along with maximum cross-linking, the CPAM-1 architecture could be more favourable whereas if a need is to achieve a maximum surface area, CPAM structural pattern could be more favourable. Owing to that, the choice of a synthetic method will depend on the desired CRF formulation as per the intended usage. Particle size analysis of the Microballs indicated that the average particles sizes as described in the mean region (Figure 6) were about $0.64 \pm 0.14 \mu \mathrm{m}$.

3.4. Nitrogen Release. Release experiments were performed as described earlier using tap water as media without further treatment. Results pertaining to the percentage of $\mathrm{N}$-released with time for a period of 30 days are presented in Figure 7. 

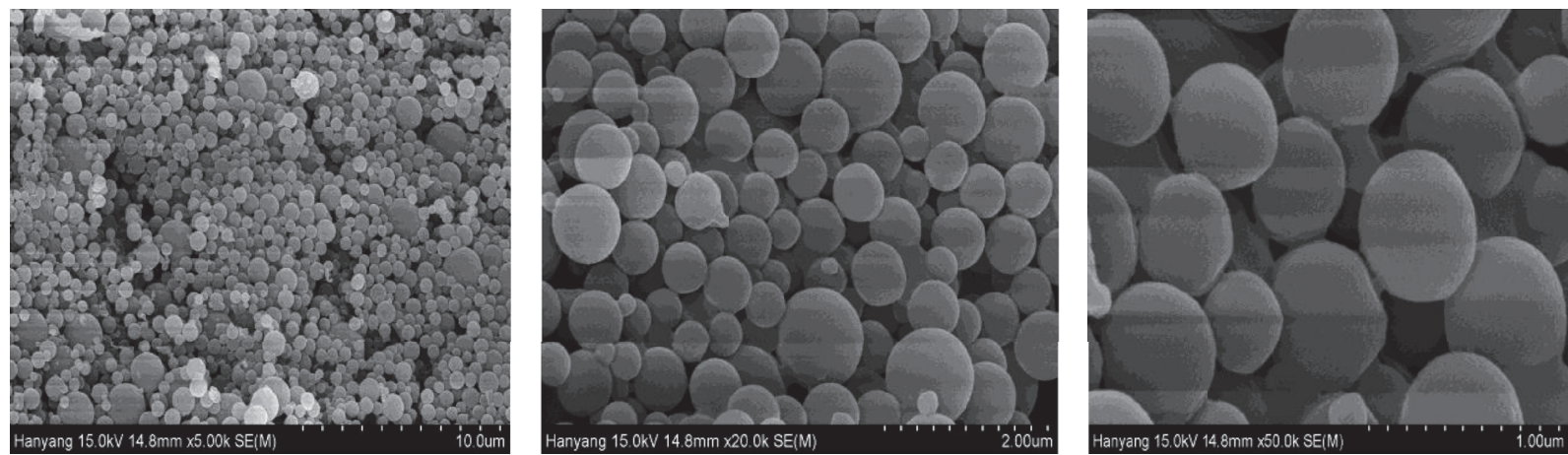

FIGURE 4: The SEM micrograms for the CPAM-1 showing the Microballs architecture.
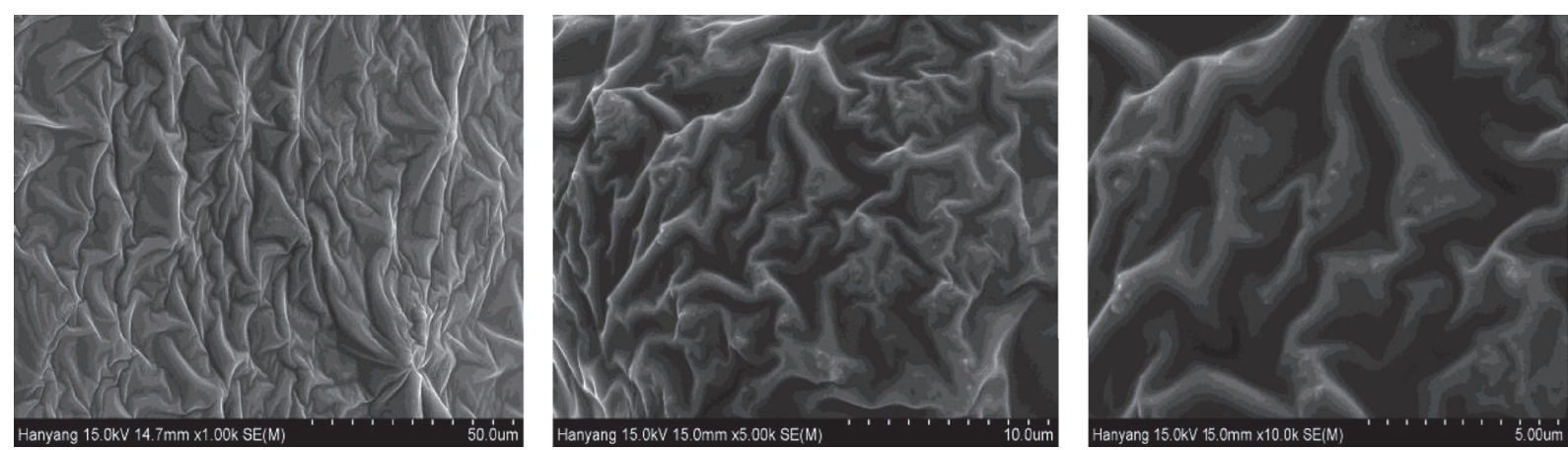

Figure 5: The SEM micrograms for the CPAM showing highly wrinkled surfaces: the Microdunes.

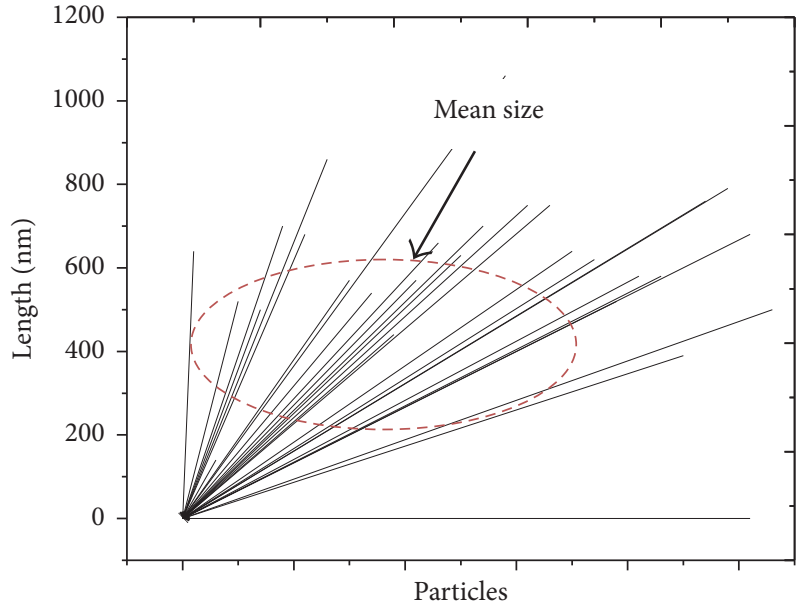

FIGURE 6: The average particle size of CRFs Microballs.

Essentially, urea release from the conventional urea fertilizer can be seen as a fast reaction which was completed in just the first day of the release trials. For CPAM-1, the release model was a linear type whereas for the CPAM the release model presented a kind of deformed sigmoid pattern due to appearance of some distorted steps in the curve' shape. As explained elsewhere in these experimental series [10], the identification of the release pattern follows the shape, lag, and lock off of the curves established. Typically, nutrient release occurs in phases [10] but in short, the phases involve water penetration creating swelling of the excipients followed by the nutrient release by a way of diffusion or connective flows via pores developed in the surfaces of the excipients. That said, the shape and the size of the resultant CRFs contribute to the release patterns, either fast release, moderate, or delayed release. In this study, morphological differences between the Microballs and Microdunes could help explain the differences in release pattern observed in Figure 7. As can be seen, sigmoid release pattern can be linked with Microdunes (for CPAM) based structures whereas the roundish Microballs (for CPAM-1) relates to linear release pattern. This study has not been able to establish the reason behind these observations, thereby calling for further investigations. According to CEN's standards, a fertilizer formulation can only be considered as a CRF if $75 \%$ of the nutrients contained can be released in 28 days at room temperature. That said, the release pattern observed in Figure 7 shows that the Microdunes and Microballs may be considered as controlled release fertilizer formulations [3].

\section{Conclusion}

Pragmatically, a clear discussion on the urea CRF formulations prepared by using chitosan, acrylamide, and urea copolymerization along with silicone doping was given. It was observed that the CRFs exhibit superior characteristics over the CCFs and so the amendments of urea CCFs via copolymerization of chitosan and acrylamide were a key step toward its commercialization as well as enhanced FUE. 


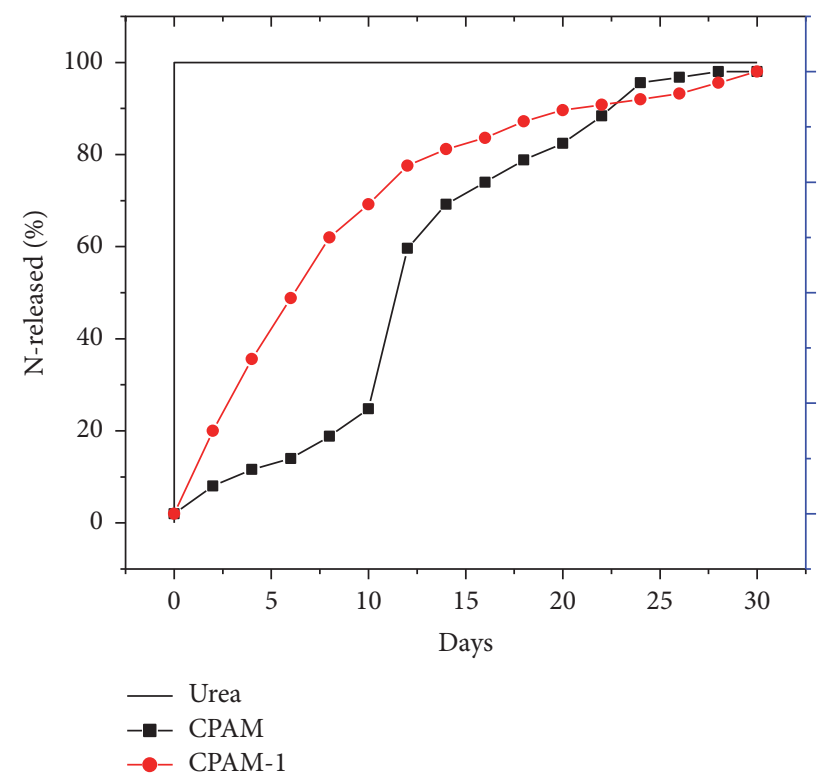

Figure 7: Release profiles for urea, CPAM, and CPAM-1 as a function of time at RT ( $\mathrm{pH} 7$ ).

Significant morphological variations were observed between the properties of urea cross-linked with and without silicone doping, thereby indicating the possibility of designing the urea fertilizer forms as per intended usage based on the climatic differences and the type of field application. The study has left several unattempted questions including the question of thermokinetic properties of the prepared CRFs formulations, release profiles under actual soil conditions with varying $\mathrm{pH}$, and properties as well as the questions regarding the formation of linear and deformed sigmoid release pattern following silicone doping. Nevertheless, the findings revealed that amendments of urea CCFs into the urea CRF formulations using excipients emanating from chitosan-acrylamide coencapsulation along with silicone doping are a feasible process.

\section{Competing Interests}

The author declares that there is no conflict of interests regarding the publication of this paper.

\section{Acknowledgments}

The author would like to thank Miss Niconia Amos Bura and the Institute of Adult Education, Tanzania, for their technical support in the preparation of this paper.

\section{References}

[1] C. J. Overdahl, G. W. Rehm, and H. L. Meredith, "Nutrient Management: Fertilizer Urea," 2015 http://www.transpakmarine.com/ static/pdf/research/ag-chemistry/UreaDescribed.pdf.

[2] D. W. James, Urea: A Low Cost Nitrogen Fertilizer with Special Management Requirements, vol. AG/283,1993, Utah State University, Logan, Utah, USA, 1993.
[3] A. Shaviv, "Advances in controlled-release fertilizers," Advances in Agronomy, vol. 71, pp. 1-49, 2001.

[4] P. M. Glibert, J. Harrison, C. Heil, and S. Seitzinger, "Escalating worldwide use of urea-a global change contributing to coastal eutrophication," Biogeochemistry, vol. 77, no. 3, pp. 441-463, 2006.

[5] C. A. Jones, R. T. Koenig, J. W. Ellsworth, B. D. Brown, and G. D. Jackson, Management of Urea Fertilizer to Minimize Volatilization, Montana State University Extension, 2007.

[6] F. Kamhabwa, Consumption of Fertilizers and Fertilizer Use by Crop in Tanzania, 2014, http://www.amitsa.org/wp-content/uploads/ bsk-pdf-manager/196_IFDC-AFO-TANZANIA-FERTILIZERCOMSUMPTION-AND-FUBC-\%28JANUARY-2014\%29-AFO .PDF.

[7] N. Minot, Fertilizer Policy and Use in Tanzania, 2009, http://fsg .afre.msu.edu/aamp/seminar_2/seminar_3_tanzania.pdf.

[8] L. Premarathna, M. J. McLaughlin, J. K. Kirby, G. M. Hettiarachchi, S. Stacey, and D. J. Chittleborough, "Selenate-enriched urea granules are a highly effective fertilizer for selenium biofortification of paddy rice grain," Journal of Agricultural and Food Chemistry, vol. 60, no. 23, pp. 6037-6044, 2012.

[9] S. I. Sempeho, H. T. Kim, E. Mubofu, A. Pogrebnoi, G. Shao, and A. Hilonga, "Encapsulated urea-Kaolinite Nanocomposite for controlled release fertilizer formulations," Journal of Chemistry, vol. 2015, Article ID 237397, 17 pages, 2015.

[10] S. I. Sempeho, H. T. Kim, E. Mubofu, and A. Hilonga, "Meticulous overview on the controlled release fertilizers," Advances in Chemistry, vol. 2014, Article ID 363071, 16 pages, 2014.

[11] T. Jamnongkan and S. Kaewpirom, "Controlled-release fertilizer based on chitosan hydrogel: phosphorus release kinetics," The Science Journal Ubon Ratchathani University, vol. 1, no. 1, pp. 43-50, 2010.

[12] L. Wu and M. Liu, "Preparation and properties of chitosancoated NPK compound fertilizer with controlled-release and water-retention," Carbohydrate Polymers, vol. 72, no. 2, pp. 240 247, 2008.

[13] S. Bhuvaneshwari, D. Sruthi, V. Sivasubramanian, K. Niranjana, and J. Sugunabai, "Development and characterization of chitosan films," IJERA, vol. 1, no. 2, pp. 292-299, 2011.

[14] I. Leceta, P. Guerrero, and K. De La Caba, "Functional properties of chitosan-based films," Carbohydrate Polymers, vol. 93, no. 1, pp. 339-346, 2013.

[15] I. Leceta, P. Guerrero, I. Ibarburu, M. T. Dueñas, and K. De La Caba, "Characterization and antimicrobial analysis of chitosanbased films," Journal of Food Engineering, vol. 116, no. 4, pp. 889899, 2013.

[16] E. Corradini, M. R. De Moura, and L. H. C. Mattoso, "A preliminary study of the incorparation of NPK fertilizer into chitosan nanoparticles," Express Polymer Letters, vol. 4, no. 8, pp. 509-515, 2010.

[17] A. Singh, P. K. Sharma, and R. Malviya, "Release behavior of drugs from various natural gums and polymers," Polimery $w$ medycynie, vol. 41, no. 4, pp. 73-80, 2011.

[18] K. Nwankwo, "Polyacrylamide as a soil stabilizer for erosion control," Madison Report, Wisconsin Department of Transportation, Madison, Wis, USA, 2001.

[19] C. V. Subbarao, G. Kartheek, and D. Sirisha, "Slow release of potash fertilizer through polymer coating," International Journal of Applied Science and Engineering, vol. 11, no. 1, pp. 2530, 2013. 
[20] S. Kumar, K. Bauddh, S. Barman, and R. P. Singh, "Evaluation of conventional and organic matrix entrapped urea and diammonium phosphate for growth and productivity of Triticum aestivum L. and mobilization of $\mathrm{NO}^{3-}, \mathrm{NO}^{2-}, \mathrm{NH}^{4+}$ and $\mathrm{PO}_{4}^{-3}$ from soil to plant leaves," International Journal of Agronomy \& Plant Production, vol. 4, no. 6, pp. 1357-1368, 2013.

[21] L. C. Carson and M. Ozores-Hampton, "Methods for determining nitrogen release from controlled-release fertilizers used for vegetable production," HortTechnology, vol. 22, no. 1, pp. 20-24, 2012.

[22] S. Kunjachan and S. Jose, "Understanding the mechanism of ionic gelation for synthesis of chitosan nanoparticles using qualitative techniques," Asian Journal of Pharmaceutics, vol. 4, no. 2, pp. 148-153, 2010.

[23] A. Dupont, M. Andriot, S. H. Chao et al., "Silicones in industrial applications," in Inorganic Polymers, D. J. Roger and G. Mario, Eds., pp. 61-161, Nova Science Publishers, Hauppauge, NY, USA, 2007.

[24] A. Groza, A. Surmeian, M. Ganciu, and I. I. Popescu, "Infrared spectral investigation of organosilicon compounds under corona charge injection in air at atmospheric pressure," Journal of Optoelectronics and Advanced Materials, vol. 7, no. 5, pp. 2545-2548, 2005.

[25] C. H. Kim, C.-K. Joo, H. J. Chun, B. R. Yoo, D. I. Noh, and Y. B. Shim, "Instrumental studies on silicone oil adsorption to the surface of intraocular lenses," Applied Surface Science, vol. 262, pp. 146-152, 2012.

[26] A. S. G. Magalhães, M. P. A. Neto, M. N. Bezerra, N. M. P. S. Ricardo, and J. P. A. Feitosa, "Application of ftir in the determination of acrylate content in poly(sodium acrylate-COacrylamide) superabsorbent hydrogels," Quimica Nova, vol. 35, no. 7, pp. 1464-1467, 2012.

[27] R. Murugan, S. Mohan, and A. Bigotto, "FTIR and polarised Raman spectra of acrylamide and polyacrylamide," Journal of the Korean Physical Society, vol. 32, no. 4, pp. 505-512, 1998.

[28] D. Ray, G. P. Mohanta, R. Manavalan, and P. K. Sahoo, "Synthesis and characterization of acrylic based copolymeric hydrogel nanoparticles: an approach to drug delivery," International Journal of ChemTech Research, vol. 1, no. 3, pp. 627-633, 2009.

[29] S.-G. Anicuta, L. Dobre, M. Stroescu, and I. Jipa, "Fourier transform infrared (FTIR) spectroscopy for characterization of antimicrobial films containing chitosan," in Analele Universitatii din Oradea Fascicula: Ecotoxicologie, Zootehniesitehnologii de Industrie Alimentara, pp. 1234-1240, 2010.

[30] J. Brugnerotto, J. Lizardi, F. M. Goycoolea, W. Argüelles-Monal, J. Desbrières, and M. Rinaudo, "An infrared investigation in relation with chitin and chitosan characterization," Polymer, vol. 42, no. 8, pp. 3569-3580, 2001.

[31] S. M. Silva, C. R. Braga, M. V. Fook, C. M. Raposo, L. H. Carvalho, and E. L. Canedo, "Application of infrared spectroscopy to analysis of chitosan/clay nanocomposites," in Infrared Spectroscopy-Materials Science, Engineering and Technology, T. Theophanides, Ed., pp. 43-62, InTech, Rijeka, Croatia, 2012.

[32] P. Fischer and C. McDowell, "The infrared absorption spectra of urea-hydrocarbon adducts," Canadian Journal of Chemistry, vol. 38, no. 2, pp. 187-193, 1960.

[33] P. Larkin, Infrared and Raman Spectroscopy; Principles and Spectral Interpretation, Elsevier, 2011.

[34] E. Horváth, J. Kristóf, and R. L. Frost, "Vibrational spectroscopy of intercalated kaolinites. Part I," Applied Spectroscopy Reviews, vol. 45 , no. 2, pp. 130-147, 2010.
[35] N. Almuslet, A. Elfatih, A. Al Sayed, and G. Mohamed, "Diode Laser $(532 \mathrm{~nm})$ induced grafting of polyacrylamide onto gum arabic," Journal of Physical Science, vol. 23, no. 2, pp. 43-53, 2012.

[36] V. V. T. Padil, N. H. A. Nguyen, A. Ševců, and M. Černík, "Fabrication, characterization, and antibacterial properties of electrospun membrane composed of gum karaya, polyvinyl alcohol, and silver nanoparticles," Journal of Nanomaterials, vol. 2015, Article ID 750726, 10 pages, 2015.

[37] G. C. Corporation, Technical Bulletin Reaction Solvent Dimethyl Sulfoxide (DMSO), 2005, http://www.gaylordchemical.com.

[38] C. C. Gaylord, Dimethyl Sulfoxide (DMSO) Physical Properties, Chemical Corporation, Slidell, La, USA, 2005.

[39] H. Becher, "Infrared spectroscopic examination of the reaction products of urea and formaldehyde. I. Methylene ureas," Chemische Berichte, vol. 89, pp. 1593-1601, 1956.

[40] Z. Piasek and T. Urbanski, "The infrared absorption spectrum and structure of urea," Bulletin de l'Academie Polonaise des Sciences. Série des Sciences Chimiques, vol. 10, pp. 113-120, 1962.

[41] M. A. Soleimani, R. Naghizadeh, A. R. Mirhabibi, and F. Golestanifard, "Effect of calcination temperature of the kaolin and molar $\mathrm{Na}_{2} \mathrm{O} / \mathrm{SiO}_{2}$ activator ratio on physical and microstructural properties of metakaolin based geopolymers," Iranian Journal of Materials Science \& Engineering, vol. 9, no. 4, pp. 43-51, 2012.

[42] U. Aroke and U. El-Nafaty, "XRF, XRD and FTIR properties and characterization of HDTMA-Br surface modified organokaolinite clay," International Journal of Emerging Technology and Advanced Engineering, vol. 4, no. 4, 2014.

[43] M. M. Dawley, A. M. Scott, F. C. Hill, J. Leszczynski, and T. M. Orlando, "Adsorption of formamide on kaolinite surfaces: A Combined Infrared Experimental And Theoretical Study," Journal of Physical Chemistry C, vol. 116, no. 45, pp. 23981-23991, 2012.

[44] C. Y. Heah, H. Kamarudin, A. M. Mustafa Al Bakri et al., "Study on solids-to-liquid and alkaline activator ratios on kaolin-based geopolymers," Construction and Building Materials, vol. 35, pp. 912-922, 2012.

[45] C. O. Mgbemena, N. O. Ibekwe, R. Sukumar, and A. R. R. Menon, "Characterization of kaolin intercalates of oleochemicals derived from rubber seed (Hevea brasiliensis) and tea seed (Camelia sinensis) oils," Journal of King Saud UniversityScience, vol. 25, no. 2, pp. 149-155, 2013.

[46] Y. M. Liew, H. Kamarudin, A. M. Mustafa Al Bakri et al., "Processing and characterization of calcined kaolin cement powder," Construction and Building Materials, vol. 30, pp. 794802, 2012.

[47] S. Park, J. O. Baker, M. E. Himmel, P. A. Parilla, and D. K. Johnson, "Cellulose crystallinity index: measurement techniques and their impact on interpreting cellulase performance," Biotechnology for Biofuels, vol. 3, article 10, 2010.

[48] M. Islam, S. M. Masum, M. M. Rahman et al., "Preparation of chitosan from shrimp shell and investigation of its properties," International Journal of Basic \& Applied Sciences, vol. 11, no. 1, 2011. 

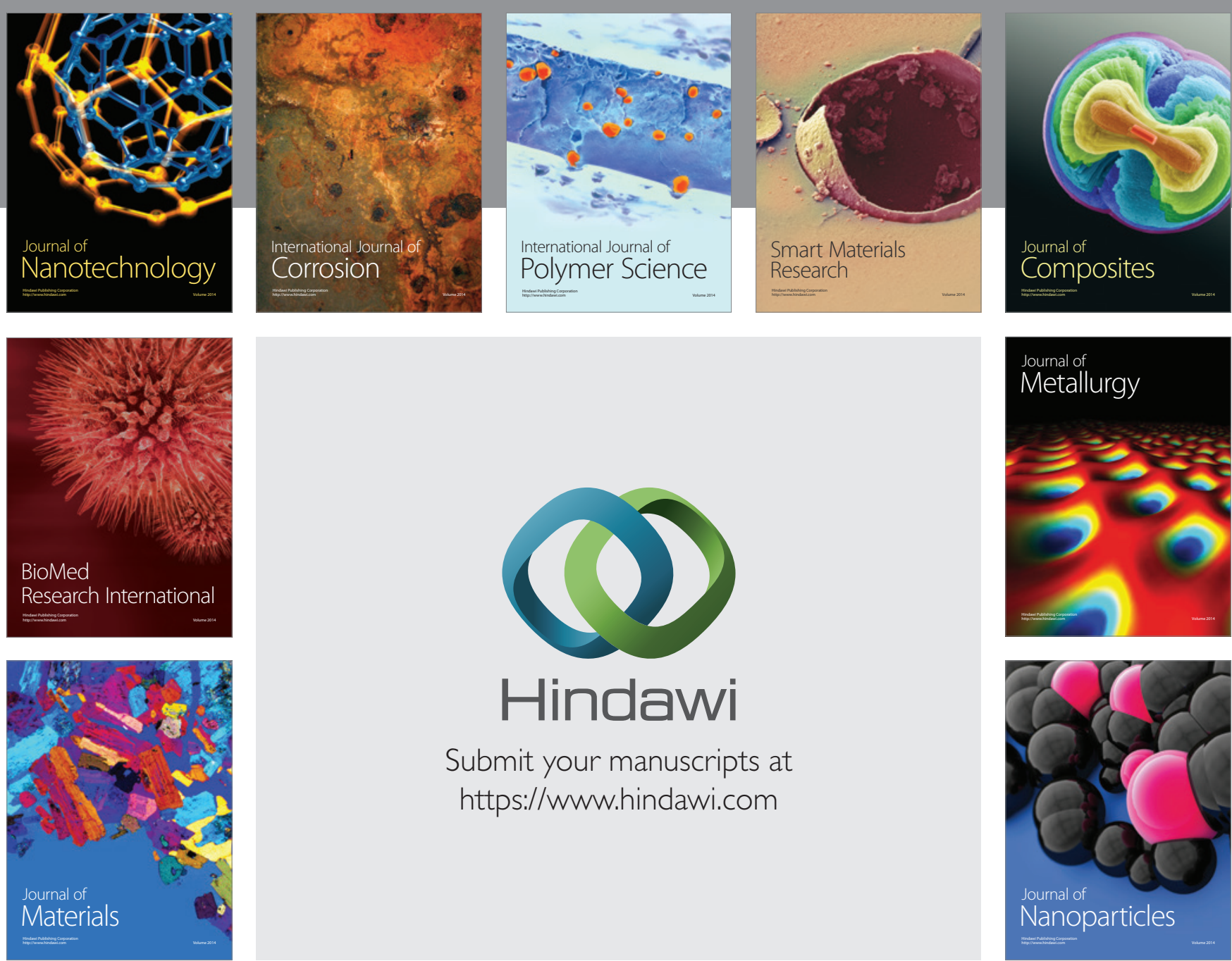

\section{Hindawi}

Submit your manuscripts at

https://www.hindawi.com

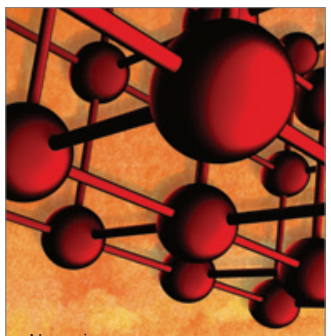

Materials Science and Engineering
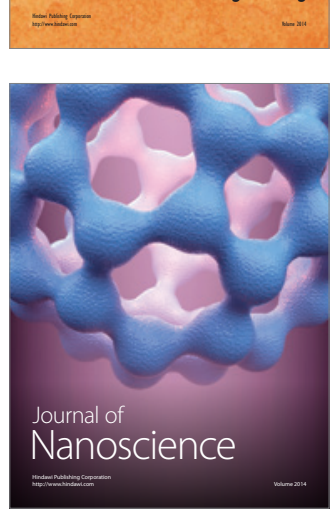
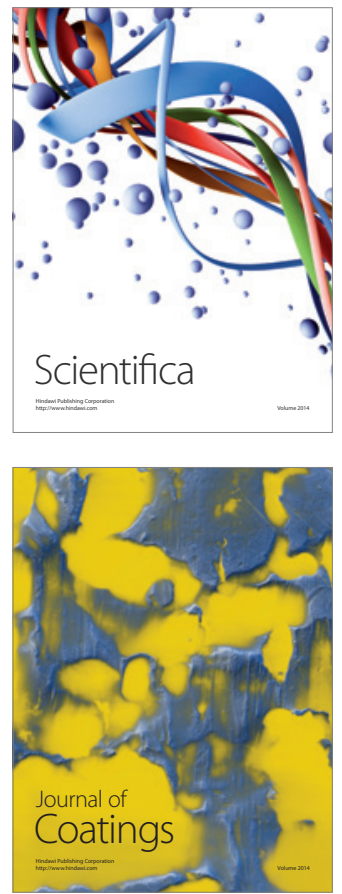
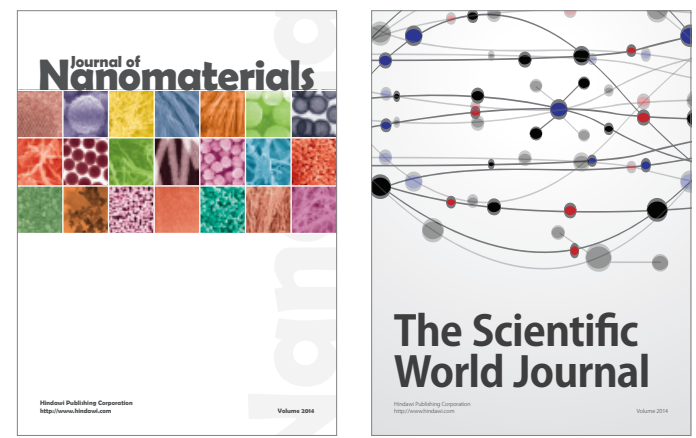

The Scientific World Journal
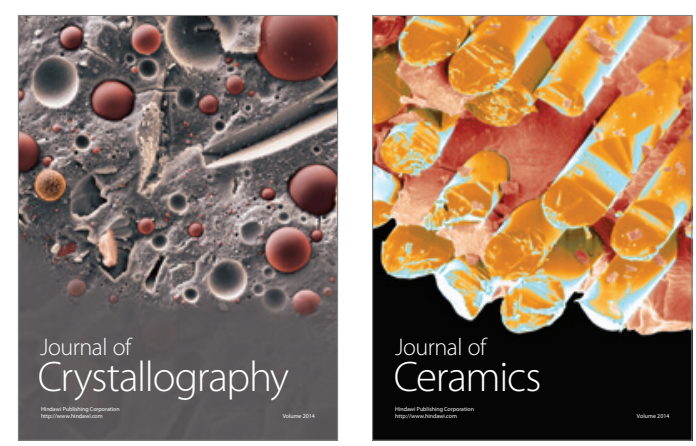
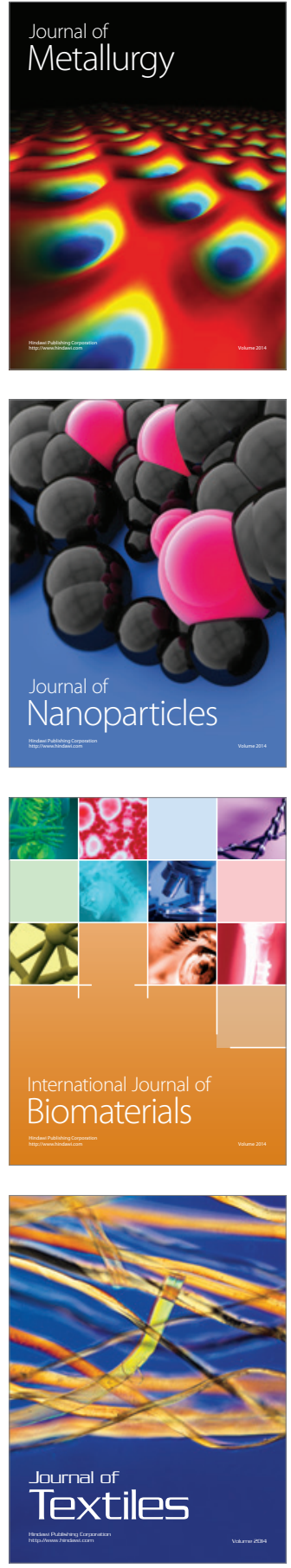